\title{
SELF-EVALUATION AND PEER EVALUATION TOOL FOR DESIGN AND ENGINEERING TEAMS: EXPERIMENT CONDUCTED IN A DESIGN STUDIO
}

\author{
Francesca MATTIOLI and Silvia FERRARIS \\ Politecnico di Milano
}

\begin{abstract}
The paper presents the results of the experimentation of a self- and peer evaluation activity conducted in a design studio of the master's of science in Design \& Engineering at Politecnico di Milano. A preliminary observation disclosed that many students are not often stimulated to reflect on the soft skills they develop through such project-based collaborative courses. This lack of self-reflection often determines a lack of awareness of their soft skills, which are very important in the contemporary work field. The research is aimed at designing a strategy to support the students' reflection through a self- and peer evaluation activity. These kinds of evaluations are widely employed in management education to assess teamwork through team member's eye. The presented experimentation is aimed at integrating the self-and peer evaluation practice in the Design \& Engineering M.Sc. The experimentation, conducted during the three-months studio, revealed that the implementation of a structured self- and peer evaluation activity could have a positive impact on team members, stimulating them to reflect on their own soft skills. Besides, the combination of self- and peer evaluation enhances the reflection and provides a ground to constructively discuss about individuals' role in teamwork. The paper presents and discusses the activity to show how it can enhance the whole learning experience.
\end{abstract}

Keywords: Self-evaluation, peer evaluation, design tools, design studio

\section{INTRODUCTION}

Soft skills are increasingly identified as necessary skills to effectively enter the work field [1]. Analysing various definitions of the term, "soft skills" are widely connected to the ability to work constructively and harmoniously with others [2][3]. Politecnico di Milano and other higher education institutions are recently supporting the innovation of teaching activities at enhancing "soft" and "social" skills within the existing educational programmes [4][5]. The School of Design is yet integrating many collaborative courses, because it adopts the design studio pedagogy model [6]. For this reason the bachelor and master programmes in design always include collaborative project-based learning activities, where students learn the design practice by doing it [7]. Being trained through collaborations, students are already improving their social and communication skills within the studio experiences [7].

Aligned with this educational approach, the Design \& Engineering master's of science fosters the consolidation of technical skills through three design studios. The course trains students to deliver high quality projects, becoming able to master the design process of new products from the problem framing (i.e. exploration, conceptualisation) to the detailing (e.g. manufacturing process, structural analysis, material selection). The course is a multidisciplinary and cross-cultural learning environment, where students are asked to collaborate with each other. This approach stimulates the development of soft skills which are highly improved by students while performing teamwork, even though they are rarely stimulated to critically reflect on the development of these type of skills. A structured moment of selfand peer evaluation could support the process of reflective practice on soft-skills [8]. This paper contributes to the design educational discourse by proposing a preliminary assessment of the impact of a structured self- and peer activity in collaborative design studio. The theme of self- and peer evaluation seems indeed very present in the management education discourse, but not very discussed in the design education one. 


\section{SELF- AND PEER EVALUATION ACTIVITY}

A self- and peer evaluation activity has been designed based on an evaluation scale from the field of management education; the intended learning outcome was to improve students' abilities in evaluating their own soft skills. The activity has been based on the Comprehensive Assessment of Team Member Effectiveness, Behaviourally Anchored Rating Scale Version, (CATME-B) which has been developed by Loughry, Ohland, and Moore [9] as a self- and peer evaluation scale system. The scale is divided into five evaluation areas, which have been identified as the most relevant to teamwork [9]:

a) Contributing to the team's work

b) Interacting with teammates

c) Keeping the team on track

d) Expecting quality

e) Having relevant knowledge, skills and abilities

Within each area, the evaluation could be scored from 1 to 5 (i.e. from low team member performance to high team member performance, see figure 1). In the adopted version, retrieved by Ohland et al. [10], behaviours are associated to each score [10] to support the evaluation process. CATME-B scale has been identified as the most suitable scale to conduct the experiment, but the activity could be re-adapted with other scales.

\begin{tabular}{|c|c|c|c|c|c|}
\hline 崫 & $\begin{array}{l}\text { This self and peer evaluation asks about how you contributed to the team during the time period you } \\
\text { are evaluating. For each way of contributing, please read the behaviours that describe a 1, 3, and } 5 \\
\text { rating. Then confidentially rate yourself. }\end{array}$ & & & & \\
\hline & Contributing to the team's work & & & & \\
\hline 5 & $\begin{array}{l}\text { - Does more or higher-quality work than expected. } \\
\text { - Makes important contributions that improve the team's work. } \\
\text { - Helps to complete the work of teammates who are having difficulty. }\end{array}$ & 5 & 5 & 5 & 5 \\
\hline 4 & Demonstrates behaviours described in both 3 and 5 . & 4 & 4 & 4 & 4 \\
\hline 3 & $\begin{array}{l}\text { - Completes a fair share of the team's work with acceptable quality. } \\
\text { - Keeps commitments and completes assignments on time. } \\
\text { - Fills in for teammates when it is easy or important. }\end{array}$ & 3 & 3 & 3 & 3 \\
\hline 2 & Demonstrates behaviours described in both 1 and 3 . & 2 & 2 & 2 & 2 \\
\hline 1 & $\begin{array}{l}\text { - Does not do a fair share of team's work. Delivers sloppy or incomplete work. } \\
\text { - Misses deadline. Is late, unprepared, or absent for team meetings. } \\
\text { - Does not assist teammates. Quits if the work becomes difficult. }\end{array}$ & 1 & 1 & 1 & 1 \\
\hline & Interacting with Teammates & & & & \\
\hline
\end{tabular}

Figure 1. Layout of the designed evaluation form. CATME-B scale retrieved by [10].

\subsection{The Structured Self-and Peer Evaluation Activity}

The activity is structured in consequential steps taking place during the teamwork experience. The steps have been structured to build a knowledge and familiarisation with the evaluation scale before using it to evaluate peers. Indeed, only the final step includes peer evaluation, while the previous steps are mainly focusing on self-evaluation.

\subsubsection{First step}

The first step takes place after the accomplishment of the first design phase. The evaluation form and the overall activity is introduced. The evaluation scale is presented, each student is provided with the printed form to be filled-in with the self-evaluation. The self-evaluation had to be performed individually without being shared with others. All the filled forms are collected and stored by the facilitator (e.g. teacher, teaching assistant).

\subsubsection{Intermediate steps}

According with the studio organisation the facilitator could set some intermediate steps. In these occasions, the students are again provided with an evaluation form and they are asked to fill it in with a self-evaluation. When they finish, the previous self-evaluation forms are individually distributed to each student allowing everyone to monitor the progress of their self-assessment. In the case of the presented experiment, there was only one intermediate step (see fig. 2). 


\subsubsection{Final step}

Students are again provided with the evaluation form (fig 1.), where they first must write their selfevaluation. Then, students make a peer evaluation about each other in the team using the same scale. Finally, each student receives:

- her own self-evaluations;

- $\quad$ peer evaluations made by others about her teamwork.

Comparing the self- and peer evaluations, each student can see any matching and mismatching of judgement. In this phase the team has time to discuss about the evaluations' results and to clarify any mismatching between self- and peer evaluations.

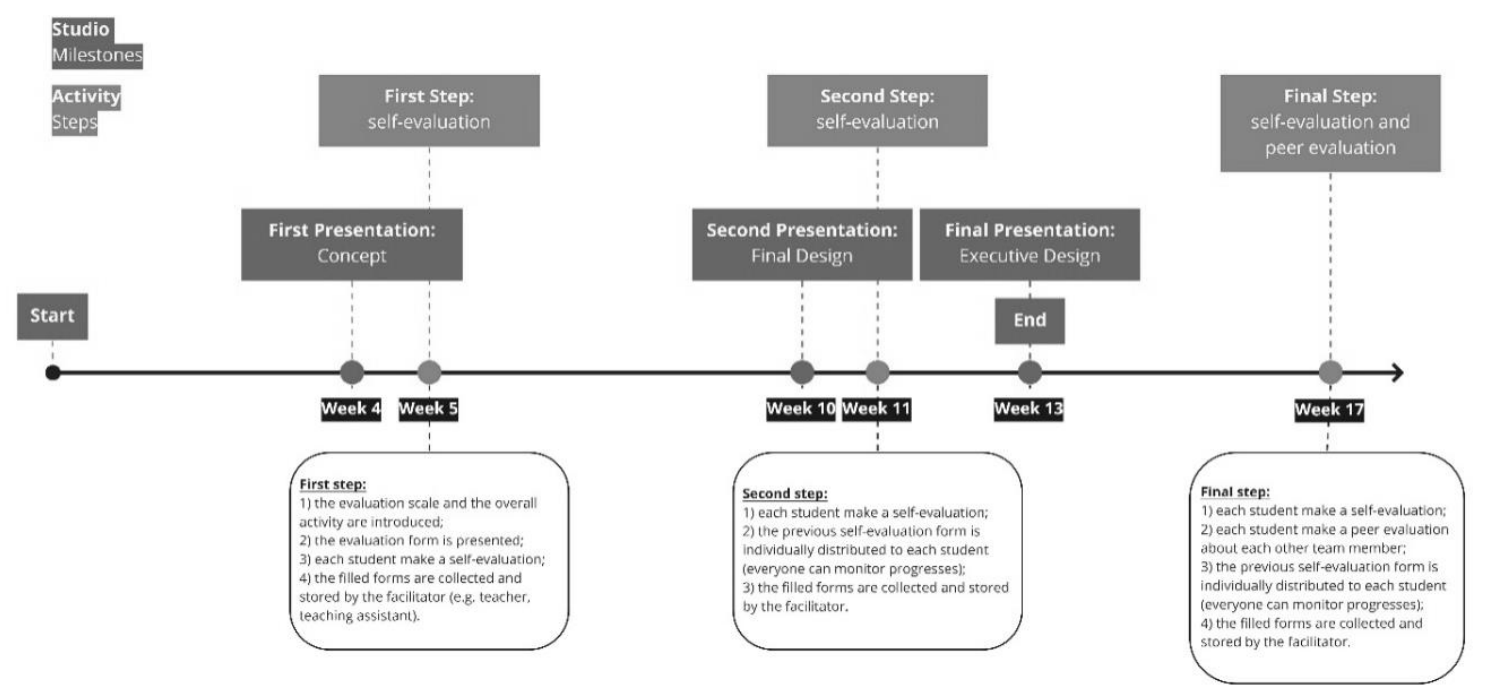

Figure 2. Diagram of the experimented activity within the design studio course

\section{THE TEST}

The tool was first drafted and preliminary tested in some previous design studio. The actual design of the tool has been outlined in September 2018 and consequently tested during the final studio of the Design and Engineering Master of Science, in which one of the authors assisted teaching. The class was composed of 45 students coming from mixed backgrounds (e.g. product design, industrial design, mechanical engineering) and different nationalities. The students were divided into 9 teams of 5 people; at the very beginning of the semester students have been free to create teams as long as there was at least one engineer in each group and there were no groups formed exclusively by international students. The board of professors provided these two grouping-up guidelines to guarantee the highest teams heterogeneity. The course aim is to synthesise all the competences acquired during the Master which is oriented towards training professionals capable of designing for manufacturing. Therefore, during this design studio, the teams are asked to design or to redesign a mid-level complexity product moving through all the design process phases, from the conceptualisation to the detailing. The design brief or the product to redesign are given by a partner company.

The board of professors is composed by a design emeritus professor, two professional product designers, a material engineering full professor, a mechanical engineering assistant professor, a professional mechanical engineer, a technical drawing expert and a teaching assistant. The professors and the professionals periodically review group projects according to a schedule agreed at the beginning of the semester; reviews are scheduled twice per week. The teaching assistant (one of the authors) must organise the schedule, facilitate communications between the students and the board of professors and to supervise the overall progress of the course. On a voluntary basis the author, while being teaching assistant, also proposed to the class the self- and peer evaluation activity.

The course last 14 weeks and the project definition passes through three main steps: Concept Presentation after 5 weeks, Final Design Presentation after 10 weeks and Executive Design Presentation after 14 weeks. The Concept Presentation should explain the conceptualisation process and present the concept, the Final Design Presentation should outline the design choices (e.g. main functions, humanproduct interaction, materials, manufacturing technologies) and the Executive Design Presentation should present the detailed design for manufacturing of the main elements of the product. The project 
advancements are presented by each team through a ten minutes presentation addressed to the board of professors, to the company representative and to the other students. After the two milestone the team are assessed:

- $\quad$ by the board of professors together with the company representative on their project, receiving a grade and feedbacks;

- $\quad$ by the teaching assistant through feedbacks on their presentation;

- $\quad$ by the other teams, receiving feedbacks on their project and presentation.

The self- and peer evaluation three main milestones were proposed shortly after each presentation and they did not influence the studio assessment.

\section{RESULTS}

The students were warmly invited to participate to the self- and peer evaluation, but, being an optional activity, not all of them were present (see table 1). For the results discussion, only the teams where at least 4 out of 5 people were present during each assessment are considered. Hence, the data related to the teams 2, 3, 6 will be presented limited to the data provided by the four students per team that attended all the assessments. The results are disclosed in the following sub-sections and are related to the selfevaluation and to the comparison between the self- and the peer evaluation. The data is in the form of series of numbers corresponding to the grades assigned during the evaluation.

Table 1. Team attendance at the self- and peer evaluations

\begin{tabular}{|c|c|c|c|c|c|c|c|c|c|}
\hline & Team 1 & Team 2 & Team 3 & Team 4 & Team 5 & Team 6 & Team 7 & Team 8 & Team 9 \\
\hline $1^{\text {st }}$ Self-evaluation & $3 / 5$ & $\mathbf{5 / 5}$ & $\mathbf{5 / 5}$ & $4 / 5$ & $5 / 5$ & $\mathbf{5 / 5}$ & $4 / 5$ & $4 / 5$ & $5 / 5$ \\
\hline $2^{\text {nd }}$ Self-evaluation & $5 / 5$ & $\mathbf{5 / 5}$ & $\mathbf{5 / 5}$ & $4 / 5$ & $5 / 5$ & $\mathbf{5 / 5}$ & $4 / 5$ & $5 / 5$ & $5 / 5$ \\
\hline $\begin{array}{c}3^{\text {rd }} \text { Self-and peer } \\
\text { evaluation }\end{array}$ & $3 / 5$ & $\mathbf{4 / 5}$ & $\mathbf{4 / 5}$ & $2 / 5$ & $2 / 5$ & $\mathbf{4 / 5}$ & $2 / 5$ & $2 / 5$ & $2 / 5$ \\
\hline
\end{tabular}

\subsection{Self-evaluation}

The data refers to the first, second and third self-evaluation steps that took place respectively after the Concept Presentation (S.E.1), after the Final Design Presentation (S.E.2) and after the Executive Design Presentation (S.E.3). Table 2 shows students self-evaluation progress by reporting the grades and the trend with respect to the previous evaluation (i.e. increasing, equal, decreasing grade). Each cell contains the student's grade, from 1 to 5 , in the corresponding CATME sections, from a) to e), per each selfevaluation step (e.g. S.E.1, S.E.2, S.E.3).

Table 2. Self-evaluations data

\begin{tabular}{|c|c|c|c|c|c|c|c|c|c|c|c|c|}
\hline \multicolumn{13}{|c|}{ Team 2} \\
\hline & \multicolumn{3}{|c|}{ Student 1} & \multicolumn{3}{|c|}{ Student 2} & \multicolumn{3}{|c|}{ Student 3} & \multicolumn{3}{|c|}{ Student 4} \\
\hline & S.E.I & S.E. 2 & S.E.3 & S.E.1 & S.E. 2 & S.E.3 & S.E.1 & S.E. 2 & S.E.3 & S.E.1 & S.E.2 & S.E.3 \\
\hline a) & 4 & $3 \downarrow$ & $\begin{array}{ll}4 & \uparrow \\
\end{array}$ & 4 & $\begin{array}{ll}5 & \uparrow \\
\end{array}$ & $5=$ & 4 & $4=$ & $4=$ & 3 & $2 \downarrow$ & 3 \\
\hline b) & 2 & $3 \uparrow$ & $3=$ & 5 & $4 \quad \downarrow$ & $4=$ & 3 & $25 \uparrow$ & $3 \downarrow$ & 2 & $\begin{array}{ll}5 & \uparrow\end{array}$ & 3 \\
\hline c) & 4 & $3 \downarrow$ & $\begin{array}{ll}4 & \uparrow \\
\end{array}$ & 4 & $4=$ & $4=$ & 3 & $\begin{array}{ll}4 & \uparrow \\
\end{array}$ & $\begin{array}{ll}5 & \uparrow \\
\end{array}$ & 3 & $3=$ & 2 \\
\hline d) & 4 & $4=$ & $4=$ & 4 & $4=$ & $3 \downarrow$ & 3 & $4 \uparrow$ & $4=$ & 2 & $3 \uparrow$ & 2 \\
\hline 7 & 4 & $4=$ & $4=$ & 5 & $5=$ & $4 \downarrow$ & 4 & $5 \uparrow$ & $4 \downarrow$ & 4 & $3 \downarrow$ & 4 \\
\hline \multicolumn{13}{|c|}{ Team 3} \\
\hline & \multicolumn{3}{|c|}{ Student 5} & \multicolumn{3}{|c|}{ Student 6} & \multicolumn{3}{|c|}{ Student 7} & \multicolumn{3}{|c|}{ Student 8} \\
\hline & S.E.I & S.E. 2 & S.E. 3 & S.E.1 & S.E. 2 & S.E.3 & S.E.1 & S.E. 2 & S.E. 3 & S.E.1 & S.E. 2 & S.E. 3 \\
\hline a) & 4 & $4=$ & $\begin{array}{ll}5 & \uparrow \\
\end{array}$ & 4 & $4=$ & $4=$ & 4 & $3 \downarrow$ & $4 \uparrow$ & 4 & $4=$ & 3 \\
\hline b) & 3 & $4 \uparrow$ & $4=$ & 3 & $3=$ & $3=$ & 3 & $44 \uparrow$ & & 4 & $4=$ & 4 \\
\hline c) & 4 & $5 \uparrow$ & $5=$ & 3 & $3=$ & $4 \uparrow$ & 4 & $4=$ & $3 \downarrow$ & 3 & $3=$ & 3 \\
\hline d) & 5 & $5=$ & $4 \downarrow$ & 4 & $3 \downarrow$ & $3=$ & 3 & & & 4 & $4=$ & 3 \\
\hline e) & 5 & $5=$ & $4 \downarrow$ & 5 & $5=$ & $4 \downarrow$ & 4 & $3 \downarrow$ & $4 \uparrow$ & 4 & $4=$ & 3 \\
\hline \multicolumn{13}{|c|}{ Team 6} \\
\hline & \multicolumn{3}{|c|}{ Student 9} & \multicolumn{3}{|c|}{ Student 10} & \multicolumn{3}{|c|}{ Student 11} & \multicolumn{3}{|c|}{ Student 12} \\
\hline & S.E. 1 & S.E.2 & S.E.3 & S.E.1 & S.E. 2 & S.E.3 & S.E.1 & S.E. 2 & S.E.3 & S.E.1 & S.E. 2 & S.E. \\
\hline
\end{tabular}




\begin{tabular}{|l|l|ll|ll|l|ll|ll|l|ll|ll|l|ll|ll|}
\hline a) & 4 & 5 & $\uparrow$ & 5 & $=$ & 3 & 4 & $\uparrow$ & 5 & $\uparrow$ & 3 & 4 & $\uparrow$ & 4 & $=$ & 3 & 4 & $\uparrow$ & 4 & $=$ \\
\hline b) & 4 & 4 & $=$ & 5 & $\uparrow$ & 4 & 5 & $\uparrow$ & 4 & $\downarrow$ & 3 & 5 & $\uparrow$ & 5 & $=$ & 4 & 3 & $\downarrow$ & 4 & $\uparrow$ \\
\hline c) & 5 & 4 & $\downarrow$ & 4 & $=$ & 3 & 4 & $\uparrow$ & 4 & $=$ & 3 & 3 & $=$ & 3 & $=$ & 4 & 4 & $=$ & 3 & $\downarrow$ \\
\hline d) & 5 & 5 & $=$ & 5 & $=$ & 3 & 4 & $\uparrow$ & 5 & $\uparrow$ & 3 & 5 & $\uparrow$ & 4 & $\downarrow$ & 3 & 3 & $=$ & 4 & $\uparrow$ \\
\hline e) & 5 & 5 & $=$ & 5 & $=$ & 3 & 4 & $\uparrow$ & 4 & $=$ & 2 & 4 & $\uparrow$ & 3 & $\downarrow$ & 3 & 4 & $\uparrow$ & 3 & $\downarrow$ \\
\hline
\end{tabular}

\subsection{Final evaluation: comparison between self- and the peer evaluation}

The data refers to the third evaluation step (S.E.3), where the students had the chance to confront their self-evaluation with the ones made by the other team members. Referring to table 3, each cell contains the value obtained by subtracting the student's self-evaluation (e.g. student 1 , student 2 , student 3 , student 4) from the assessment made by one of the other group members (e.g. P.E.1, P.E.2, P.E.3). It follows that a value equal to zero corresponds to a self-evaluation aligned to the one made by a peer; a value less than zero corresponds to an overestimation of oneself and a value greater than zero corresponds to and underestimation.

Table 3. Peer evaluations and third self-evaluation subtraction

\begin{tabular}{|c|c|c|c|c|c|c|c|c|c|c|c|c|}
\hline \multicolumn{13}{|c|}{ Team 2} \\
\hline & \multicolumn{3}{|c|}{ Student 1} & \multicolumn{3}{|c|}{ Student 2} & \multicolumn{3}{|c|}{ Student 3} & \multicolumn{3}{|c|}{ Student 4} \\
\hline & P.E.1 & P.E. 2 & P.E.3 & P.E.1 & P.E. 2 & P.E.3 & P.E.1 & P.E. 2 & P.E.3 & P.E.1 & P.E.2 & P.E.3 \\
\hline a) & 0 & -1 & -1 & $\mathbf{0}$ & $\mathbf{0}$ & -1 & -1 & -2 & 1 & 0 & $\mathbf{0}$ & 1 \\
\hline b) & 1 & 0 & 1 & -2 & -1 & -1 & -1 & $\mathbf{0}$ & $\mathbf{0}$ & 0 & 1 & $\mathbf{0}$ \\
\hline c) & 0 & -2 & -1 & 1 & 1 & $\mathbf{0}$ & -2 & -3 & -2 & $\mathbf{0}$ & 1 & 1 \\
\hline d) & -1 & -2 & -2 & 1 & 1 & 1 & -1 & 0 & 0 & $\mathbf{0}$ & 1 & 1 \\
\hline e) & 0 & -2 & -2 & 1 & 0 & 1 & 0 & -1 & 1 & $\mathbf{0}$ & $\mathbf{0}$ & -1 \\
\hline \multicolumn{13}{|c|}{ Team 3} \\
\hline & \multicolumn{3}{|c|}{ Student 5} & \multicolumn{3}{|c|}{ Student 6} & \multicolumn{3}{|c|}{ Student 7} & \multicolumn{3}{|c|}{ Student 8} \\
\hline & P.E.1 & P.E.2 & P.E.3 & P.E.1 & P.E.2 & P.E.3 & P.E.1 & P.E.2 & P.E.3 & P.E.1 & P.E.2 & P.E.3 \\
\hline a) & $\mathbf{0}$ & -1 & $\mathbf{0}$ & 1 & 1 & $\mathbf{0}$ & -1 & -1 & $\mathbf{0}$ & $\mathbf{0}$ & 1 & 1 \\
\hline b) & 1 & 1 & 0 & $\mathbf{0}$ & 1 & -1 & 1 & 1 & $\mathbf{0}$ & -1 & -1 & $\mathbf{0}$ \\
\hline c) & $\mathbf{0}$ & -1 & 0 & 0 & 0 & -1 & 1 & 0 & 0 & 1 & 2 & 1 \\
\hline d) & 1 & 1 & $\mathbf{0}$ & $\mathbf{0}$ & 2 & 1 & -1 & -1 & 0 & 1 & 1 & 1 \\
\hline e) & 1 & 1 & 1 & 1 & 1 & 1 & -1 & -1 & -1 & $\mathbf{0}$ & $\mathbf{0}$ & $\mathbf{0}$ \\
\hline \multicolumn{13}{|c|}{ Team 6} \\
\hline & \multicolumn{3}{|c|}{ Student 9} & \multicolumn{3}{|c|}{ Student 10} & \multicolumn{3}{|c|}{ Student 11} & \multicolumn{3}{|c|}{ Student 12} \\
\hline & P.E.1 & P.E.2 & P.E.3 & P.E.1 & P.E.2 & P.E.3 & P.E.1 & P.E. 2 & P.E.3 & P.E.1 & P.E.2 & P.E.3 \\
\hline a) & $\mathbf{0}$ & $\mathbf{0}$ & 0 & 0 & 0 & 0 & $\mathbf{0}$ & 1 & 1 & $\mathbf{0}$ & $\mathbf{0}$ & 1 \\
\hline b) & -1 & 0 & -1 & 1 & 0 & 1 & 0 & 0 & 0 & 1 & 1 & 1 \\
\hline c) & 1 & $\mathbf{0}$ & $\mathbf{0}$ & 0 & 1 & 1 & 1 & 1 & 2 & 1 & 1 & 2 \\
\hline d) & $\mathbf{0}$ & $\mathbf{0}$ & $\mathbf{0}$ & $\mathbf{0}$ & $\mathbf{0}$ & $\mathbf{0}$ & 1 & 1 & 1 & 0 & 0 & 1 \\
\hline e) & $\mathbf{0}$ & 0 & $\mathbf{0}$ & 1 & 1 & 1 & 1 & 1 & 1 & 1 & 1 & 2 \\
\hline
\end{tabular}

\section{DISCUSSION}

The results shown in table 2 and 3 are useful to understand the final overview that each student was able to outline about her own soft skills. Indeed, each of them could see the self-evaluation progress through the three months and could compare the last one with the peers' one. Since the major objective of the experiment was to understand the degree of self-awareness on soft skills and to stimulate a reflection about that, it was explained to student that the most relevant outcome they could have gathered was related to the coherence between self- and peer evaluation, in other words, they could have been satisfied if their last self-assessment had not been very different from those of their team mates. From Table 3, emerges that Student 9, Student 4 and Student 5 were very accurate in their self-evaluations. On the contrary Student 1 and Student 3 overestimated their selves, while Student 10 and Student 11 tended to underestimate themselves. Then, the students were asked to give feedbacks to each other related to their peer evaluations. This discussion was very important to build awareness, enabling students to identify strength and weak points in the way they collaborated and to consequently stimulate future self- 
improvement goals. During this phase to some arguments occurred, especially in those cases in which students had overestimated themselves (e.g. in team 2 between Student 1 and 2, in team 3 between Student 5 and 8). The last reflection input gave to the students was to consider the growth path outlined by the three self-assessment, especially in the light of the peers' evaluation: was the whole selfevaluation path coherent with the feedbacks received by peers?

At the end of the activity, students were asked to give some feedbacks about the activity and most of them were positive. Most of the class argued that the self- and peer evaluation helped to collectively understand the teams' problems and to better assess how to improve individuals' contribution to teamwork. Some other students stated that the activity was helpful to better understand the other team members. A small part of students was partially unsatisfied with the activity for different reasons; somebody felt uncomfortable in grading others, somebody else suggested to anticipate the peer evaluations from the first step, some other complained about team members absence during the activity steps. Even though this was only a first attempt to integrate this kind of activity in our studios, data collected either through our observations and student's feedbacks shows that the activity provided a new space for growing awareness on soft skills. Moreover, self-reflection seems to be even more grounded and enhanced by peer evaluation and the following discussion.

\section{CONCLUSIONS}

The paper disclosed the potential of integrating a self- and peer evaluation activity in design studios to stimulate students' reflection on their soft skills, highlighted as crucial skills for professional. The proposed activity is a first attempt to train students to identify positive behaviours that enhance teamwork, reflecting first on themselves, then on others and, finally, to compare the two. Even though the activity should be tested on a larger sample, the feedbacks were positive, and the observations confirmed our initial hypothesis. The activity, indeed, was useful to support students while critically assessing the soft skills acquired during the design studio experience.

After this preliminary investigation, further studies should assess the effect similar activities when proposed during throughout the whole study path. Also, the authors are looking for solutions to involve all student in the activity. One way could be by showing them the advantages of such extra work. Another option could be to make the activity mandatory as part of the course, which is something to be considered for the future.

\section{REFERENCES}

[1] Davies A., Fidler D. and Gorbis M. "Future Work Skills 2020," Inst. Futur., p. 14, 2011.

[2] Oxford University Press, "soft skills | Definition of soft skills in English by Oxford Dictionaries," 2019. [Online]. Available: https://en.oxforddictionaries.com/definition/soft_skills. [Accessed: 11Mar-2019].

[3] Cambridge English, "SOFT SKILLS | meaning in the Cambridge English Dictionary," 2019. [Online]. Available: https://dictionary.cambridge.org/dictionary/english/soft-skills. [Accessed: 10Mar-2019].

[4] EHEA, "Employability of graduates," European Higher Education Area and Bologna Process, 2016. [Online]. Available: http://www.ehea.info/pid34423-cid102525/employability-ofgraduates.html. [Accessed: 20-May-2019].

[5] Politecnico di Milano, "Politiche di Ateneo e Programmazione Offerta Formativa AA 2018/19," Milano, 2018.

[6] Dutton T.A. "Design and Studio Pedagogy," J. Archit. Educ. , vol. 41, no. 1, pp. 16-25, 1987.

[7] Tracey M.W. and Boling E. "Preparing instructional designers: Traditional and emerging perspectives," in Handbook of Research on Educational Communications and Technology: Fourth Edition, 2014.

[8] Sluijsmans D., Dochy F. and Moerkerke G. "Creating a learning environment by using self-, peerand co-assessment," 1999.

[9] Loughry M.L., Ohland M.W. and Moore D.D. "Development of a Theory-Based Member Effectiveness," Educ. Psychol. Meas., vol. 67, no. 3, pp. 505-524, 2007.

[10] Ohland M.W. et al. "The comprehensive assessment of team member effectiveness: Development of a behaviorally anchored rating scale for self- and peer evaluation," Acad. Manag. Learn. Educ., vol. 11, no. 4, pp. 609-630, 2012. 